\title{
Estimation of heritability, breeding values and genetic trends for growth traits of exotic goat
}

\author{
Hassan MR ${ }^{1,2^{*}}$, Sultana $\mathrm{S}^{1}$, Iqbal $\mathrm{A}^{3}$ and Talukder $\mathrm{MAI}^{2}$ \\ ${ }^{1}$ Department of Animal Science, Chonbuk National University, Jeonju 561-756, South Korea, ${ }^{2}$ Bangladesh \\ Livestock Research Institute, Savar, Dhaka-1341 and ${ }^{3}$ Department of Genetic Engineering and biotechnology, \\ Shahjalal University of Science and Technology, Sylhet, Bangladesh
}

[Received: April 10, Accepted: December 20, 2013]

\begin{abstract}
The present study was considered to estimate the variance components, heritability and prediction of breeding values (PBV) for important growth traits of exotic goat. Traits were considered birth weight, weaning weight, 6 months weight and weight at 9 months. Data were collected from the goat farm of Bangladesh livestock research institute (BLRI), Savar, Dhaka. Heritability values for the studied traits were estimated by Multivariate animal model using principles of Restricted Maximum Likelihood (REML) procedure. The mean birth weight, weaning weight, 6 and 9 months weight of exotic goat were recorded as 1.41, 7.39, 11.06 and $14.09 \mathrm{kgs}$ respectively. Calculated Heritability values were $0.33,0.39,0.45$ and 0.32 for the birth weight, weaning weight, and weight at 6 and 9 month respectively. Heritability estimates for different growth traits of exotic goat were found higher but the highest for the 6 month body weight (0.45). Among the live weight categories of exotic goat the maximum average PBV was found for the 6-month body weight (7.42). The genetic trends among the generations in birth and 6 month weight were increased from foundation to generation 1 and 2. Therefore, the results revealed that the 6 month's body weight can be considered as an indicator of growth and sire selection and could be effective for enhancing growth of exotic kids.
\end{abstract}

Key Words: Heritability, Birth weight, weaning weight, 6 \& 9 months weight and exotic goat

\section{INTRODUCTION}

The goat population in Bangladesh is composed mainly of Black Bengal and also has some exotic goat. In Bangladesh, exotic bucks are being imported personally by the farmers from India and used for crossbreeding. Therefore, the actual number is unknown but most exotic goat found in southwestern part of the country ${ }^{[1]}$. The growth potential of the kids is one of the most important traits in a genetic improvement scheme. Meanwhile, the profitability of goat production for meat is largely depends on kid weight as the growth performance. The growth performance of a kid determines the meat production ability of the kid up to a marketable age. Therefore, several authors have shown that both direct and maternal influences are important for animal growth ${ }^{[2-5]}$. These maternal effects reflect the dam's milk production and mothering ability. Therefore, to determine optimal breeding strategies to increase the efficiency of goat production, knowledge of genetic parameters for weight traits at various ages and also the relationships between traits is needed ${ }^{[6]}$. The genetic trend influenced due to change in mean breeding value of an animal and which would be an indicator to determine success or failure of any kind of breeding program. Therefore, it is important to estimate genetic parameters before the development of breeding strategies specific to Bangladesh conditions. Thus, the present study was undertaken to evaluate heritability and breeding values of growth traits of exotic goat.

\section{MATERIALS AND METHODS}

The study was conducted at the goat farm of Bangladesh Livestock Research Institute, Savar, Dhaka. Data collected on the exotic flock over the period of July'06- June'2010. Exotic goats (Jamunapari, Jamunapari x Black Bengal, Beetal, Beetal x Black Bengal, Sirohi, Sirohi x Black Bengal) were reared under semi-intensive feeding where they are allowed to graze during the day for 5 to 6 hours, excepting during the rain and inclement weather and supplemented with concentrate $(300 \mathrm{~g} / \mathrm{animal} / \mathrm{d})$ or seasonally available green and dry fodders. Generally controlled mating is practiced. Normally one breeding buck is allowed to mate with 20 to 25 does. Does are kept in kidding pen under close observation and proper care for three to four days prior to the expected date of parturition. At kidding both kids and does were weighed, and the kidding date, sex, and parity of each kid were recorded. Kids were weighed at 15 days interval from birth to weaning at 3 months of age and thereafter at monthly intervals up to 9 months of age. Normally kids were weaned at 3 months of age. Goats were vaccinated against common diseases like peste des petits ruminants (PPR), Foot and Mouth Disease (FMD), Enterotoxaemia and Hemorrhagic Septicemia.

Data available for analysis were collected from the flock of exotic goat maintained at goat farm of Bangladesh Livestock Research Institute, Savar, Dhaka on 415 half-sib kid progenies from 15 bucks 
and 112 does were used in this study (Table 1). The traits considered in the present study were weight at birth, weaning weight, 6 months weight and weight at 9 months of age in exotic goat. Growth performance data were recorded in the register and were used for statistical analysis using Statistical package for Social Science (SPSS 11.5).

Table1. Characteristics of growth trait and data structure of exotic goat animal's breeding value; $\mathrm{c}$ is the unknown vector of season of birth and e is the vector of residual effects.

\section{RESULTS AND DISCUSSION}

Mean and standard error (SE) of different growth traits are shown in Table 1 . The average birth weight, 3,6 and 9 months of weight were 1.6, 7.9, 13.56, and $17.76 \mathrm{kgs}$ respectively. Rout et al ${ }^{[9]}$ reported that the weight of exotic kids are $2.7 \mathrm{kgs}$ at birth, $12.3 \mathrm{kgs}$ at 3 months, $16 \mathrm{kgs}$ at 6 month, and $22 \mathrm{kgs}$ at 9 months.

\begin{tabular}{lcccc}
\hline \multirow{2}{*}{ Item } & \multicolumn{4}{c}{ Body weight } \\
\cline { 2 - 5 } & Birth & 3 month & 6 month & 9 month \\
\hline Average weight (Kg) & 1.60 & 7.90 & 13.56 & 17.76 \\
Standard Error & 0.60 & 2.30 & 3.50 & 3.90 \\
CV (\%) & 36 & 20 & 15 & 13 \\
No of records & 469 & 447 & 296 & 178 \\
Progeny per sire & 22.08 & 21.04 & 20.89 & 20.01 \\
Progeny per dam & 5.80 & 5.49 & 5.18 & 5.08 \\
\hline
\end{tabular}

Covariance components were estimated using by multivariate animal model using the principles of Restricted Maximum Likelihood (REML) through computer program VCE 4 Version VCE 4.2.5 ${ }^{[8]}$. Breeding value (BV) was estimated by the Best Linear Unbiased Prediction (BLUP) methods of Henderson ${ }^{[7]}$ by the PEST (Prediction estimation) computer program of Groenveld ${ }^{[8]}$. However, for all traits analyses were carried out both within genetic group as well as over the genetic groups i.e. pooled data. For REML analyses, a multivariate animal model was used keeping year of birth, sex (male and female), type of birth (single, twin) and age of dam as fixed effects.

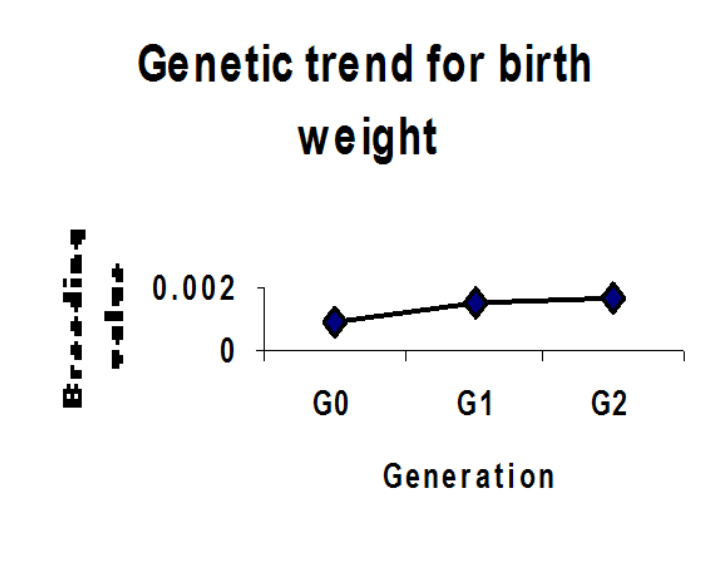

The following mixed model equation was used: $\mathrm{Y}=\mathrm{Xb}+\mathrm{Za}+\mathrm{Wc}+\mathrm{e}$

Where, $\mathrm{Y}$ is the vector of observation; $\mathrm{X}, \mathrm{Z}$ and $\mathrm{W}$ were the known incidence matrices that is associated with levels of $\mathrm{b}$, a and $\mathrm{c}$ with $\mathrm{Y}$; $\mathrm{b}$ is the unknown vector of year of birth; $a$ is the unknown vector of
On the other hand, Patnaik and Nayak ${ }^{[10]}$ found that the birth and 3 month weight of exotic kid is $2.28 \pm 0.14$ and $9.38 \pm 0.55 \mathrm{kgs}$ respectively, which is higher than that of the present findings. It might be due to the admixture of blood with Black Bengal, Jamunapari, Betal and other goat breeds. Furthermore, Patnaik and Nayak ${ }^{[10]}$ added that birth weight also influenced by the sex of the kid and which also corresponds with our previous results of Hassan et al ${ }^{[11]}$.

\section{Genetic trend for 3 month body weight}

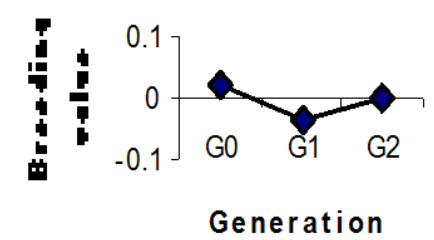

Heritability estimates for birth weight, weaning weight and weight at 6 and 9 months of age in exotic goat are summarized in Table 2. The heritability value was calculated as 0.33 for birth weight which was higher than that of other studies [12-15]. An estimation of heritability for the birth weight of 0.29 was reported by Roy et al ${ }^{[16]}$ in Jamunapari goats and which corresponds with the present findings. In another results, Aziz and Schaeffer ${ }^{[17]}$ estimated heritability for birth weight of Sauffolk and Dorset 
lambs is 0.33 and 0.27 and which agrees with the present results. However higher heritability estimates for birth weight have been reported for some other goat breeds [18, 19]. Heritability estimate for birth weight was lower to the estimates of 0.18 reported by Al-Shorepy et al ${ }^{[20]}$ in Emirati goat and 0.14 in Boer goats ${ }^{[21] .}$ Meanwhile, due to lack of previous studies regarding the growth traits of exotic goat in Bangladesh, a direct comparison was difficult. However, the possible reason of variation might be that the differences in breed and environmental conditions under which different breeds were maintained.

The heritability estimate for weaning weight in the present study was 0.39 which is lower than the estimates of Roy et al ${ }^{[22]}$ on exotic goat and AlShorepy ${ }^{[20]}$ on local breed of sheep. Therefore the present analyses suggested that after weaning, maternal permanent environmental effects were still an important source of variation.

Table 2. Estimates of variance components for growth traits of exotic goat months of age, but were no longer important at 12 months.

\section{Genetic trend for 6 month body w eight}
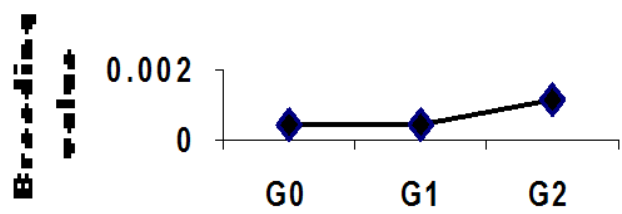

Generation

Predicted breeding value (PBV) for birth weight, 3, 6 and 9-month weight of exotic goat are shown in Table 3. Among the live weight categories of exotic goat, the maximum average PBV was found for the 6-month body weight (7.418). Akhter et al ${ }^{[25]}$ found that the maximum predicted breeding values of

\begin{tabular}{llll}
\hline \multirow{2}{*}{ Parameter $(\mathrm{kg})$} & \multicolumn{2}{l}{ Variance components } & \multirow{2}{*}{$\mathrm{h}^{2}$} \\
\cline { 2 - 4 } & $\sigma_{\mathrm{A}}{ }^{*}$ & $\sigma_{\mathrm{P}}^{2}{ }^{*}$ & 0.564 \\
\hline Birth weight & 0.189 & 0.394 & 0.39 \\
3 month weight & 1.427 & 8.346 & 0.45 \\
6 month weight & 3.773 & 14.69 & 0.32 \\
9 month weight & 4.712 & &
\end{tabular}

In the present study, heritability estimates of 6 months weight was 0.45. Mokhtaria et al [23] mentioned that heritability estimates for 6 months weight was as 0.32 , which agrees with the present result. In contrast, Roy et al ${ }^{[22]}$ found that the direct heritability for post weaning weights was 0.13 which is lower than the present findings. In another experiment, Leo et al ${ }^{[24]}$ estimated that heritability for weight at 6 month is $0.21 \pm 0.03$, which is also lower than the present study. It could be happened due to the breed, environment and also geographical variation among the results.

The heritability estimate for the weight at 9 months of age was found to be as high as 0.32 in the present study and which supported by the results of Snyman et al ${ }^{[3]}$ who found the heritability of weight at 8 month of age was as $0.59 \pm 0.06$, which agrees with the present investigation. Roy et al ${ }^{[22]}$ found that the heritability estimate for the 9 months of age was 0.21 in Jamunapari goat, which is lower than the present findings. Thus the present results suggested that after weaning, maternal permanent environmental effects were still an important source of variation up to 9
Black Bengal goat was found for the 6 month body weight, which is similar with the present findings.

Therefore the present results suggested that further selection and breeding of exotic goat should be based on 6 month body weight basis.

\section{Genetic trend for 9 month body weight}

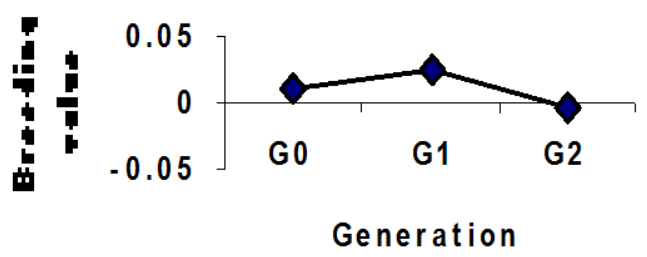

The genetic trends among the generations of exotic goat for birth weight, 3, 6 and 9-month body weight 
are presented in Figure1, 2, 3 and 4. In birth and 6 month weight there were an increased breeding value in foundation, which gradually increases in generation 1 and 2 . In case of 3 month, breeding value was decreased in generation 1 but increase in generation 2 where reverse in 9-month body weight. Akhter et al ${ }^{[25]}$ reported that in Black Bengal goat that breeding value was decreased in the first generation, which gradually increased in generation 2 and 3. The differences in the present study and those of other investigators might be due to the differences in breed and environmental conditions under which different breeds were maintained. These differences in the results obtained might also be due the methods employed for the estimation heritability.

Table 3. Range of predicted breeding value of exotic goat
5. Matika O, Van Wyk JB, Erasmus GJ and Baker RL (2003). Genetic parameter estimates in Sabi sheep. Livestock Production Science. 79: 17-28.

6. Chapman AB (1995). General and Quantitative genetics, Elsevier Science Publishers. B.V. Amsterdam, USA. pp.92.

7. Henderson CR (1973). Sire evaluation and genetic trends. Journal of Animal Science. 10-41.

8. Groeneveld, E. VCE 4.2.5 (1998). user's guide and reference manual version 1.1. Institute of Animal Husbandry and Animal Behaviour, Mariensee, Federal Agricultural Research Centre, Germany.

\begin{tabular}{llll}
\hline \multirow{2}{*}{ Parameter $(\mathrm{kg})$} & \multicolumn{4}{l}{ Range of estimated BV } \\
\cline { 2 - 4 } & Min. & Max. & Average \\
\hline Birth weight & -1.160 & 1.380 & -0.0085 \\
3 month weight & -2.270 & 3.739 & -0.0126 \\
6 month weight & -6.670 & 7.418 & 0.0138 \\
9 month weight & -7.251 & 6.970 & 0.0038 \\
\hline
\end{tabular}

\section{CONCLUSION}

The results revealed that the 6 month body weight could be considered for selection and which could be effective for enhancing growth of exotic goat. So, improvement for those selected traits could be achieved by individual selection or performance testing. Therefore, the selection program should be continued with larger flock size.

\section{REFERENCES}

1. Faruque MO and Khandoker MAMY (2007). Recent advances of goat genotyping in Bangladesh. In proceeding: Workshop on recent advances of livestock genotyping in Bangladesh. Genotyping of goats and buffaloes for breed and type determination. May 10, Dhaka. pp: 28-40.

2. Maria GA, Boldman KG and Van Vleck LD (1993). Estimates of variance due to direct and maternal effect for growth traits of Romanov Sheep. Journal of Animal Science. 71: 845-849.

3. Synman MA, Erasmus GJ, Wyk JBV and Olivier JJ (1995). Direct and maternal (co) variance components and heritability estimates for body weight at different ages and fleece traits in Afrino sheep. Journal of Livestock Production Science. 44: 229-235.

4. Nasholm A and Danell O (1996). Genetic relationship of lamb weight, maternal ability, and mature ewe weight in Swedish finewool sheep. Journal of Animal Science.74: 329-339.
9. Rout PK, Mandal A, Roy R and Singh LB (1999). Improvement and conservation of Exotic goats in their home tract. India Ministry of Agriculture Report, New Delhi, India.

10. Patnaik RK and Nayak S (1988). Growth rate and survivability patterns in Black Bengal, Ganjam and Exotic breeds of goats under farm conditions in Orissa. Indian Journal of Animal Science. 58: 1442-1445.

11. Hassan MR, Talukder MAI and Sultana S (2010). Evaluation of the production characteristics of the jamunapari goat and its adaptability to the farm condition in Bangladesh. The Bangladesh Veterinarian. 27: 26-35.

12. Chaudhry MZ and Shah SK (1985). Heritability and correlation of birth weight, weaning weight and 12 months weight in Lohi, Awassi, Hissardale and Kachhi sheep. Pakistan Veterinary Journal. 5: 67-71.

13. Maui V and Rodricks IM (1988). Production performance of Merino Nilagiri crossbred sheep birth and weaning weights. Animal Breeding Abstract. 56: 3612 .

14. Bromley CM, Snowder GD, Vleck LD and VanVleck LD (2000). Genetic parameters among weight, prolificacy, and wool traits of Colombia, Polypay, Rambouillet and Targhee sheep. Journal of Animal Science.78: 846-858. 
15. Sarti FM, Panella F and Bogani D (2001). The most suitable traits in Appenninica sheep for meat selection. Zootinica-e-Nutrizone Animale. 27: 65-73.

16. Roy R, Singh SK, Rout PK, Saxena VK and Khan BU (2003). Genetic trend of growth of Exotic kids. Indian Journal of Animal Science.73: 534-537.

17. Aziz, DA and Schaeffer LR (1988). Effects of sex, age of dam and type of birth, rearing status on growth traits of Suffolk and Dorset lambs. In Annual Report, Centre for Genetic Improvement of Livestock, Department of Animal and Poultry Science, Ontario Agricultural College, University of Guelph. Guelph, Canada. Animal Breeding Abstract. 56: 194.

18. Mavrogenis AP, Constantinou A and Louca A (1984). Environmental and genetic causes of variation in production traits of Damascus goats. 1. Preweaning and post weaning growth. Animal Production. 38: 91-98.

19. Malik CP, Kanaujia AS and Pander BL (1986). A note on the factors affecting pre weaning growth in Beetal and Black Bengal kids and their crosses. Animal Production. 43: 178-182.

20. AL-Shorepy SA (2001). Genetic parameters for growth traits of a local breed of sheep in the
United Arab Emirates. The Journal of Agricultural Science. 137: 365-371.

21. Schoeman SJ, Els JF and Van Niekerk MM (1997). Variance components of early growth traits in the Boer goat. Small ruminant research. 26: $15-20$.

22. Roy R, Mondal A and Notter DR (2008). Estimate of (co)variance components due to direct and maternal effects for body weights in Exotic goats. Animal. 2: 354-359.

23. Mokhtaria MS, Rashidib A and Mohammadic Y (2008). Estimation of genetic parameters for post-weaning traits of Kermani sheep. Small Ruminant Research. 80: 22-27.

24. Leo LLP, Gopal RG, Chopra A and Arora AL (2010). Estimates of (co)variance components and genetic parameters for growth traits of Avikalin sheep. Tropical Animal Health and Production. doi 10.1007/s11250-010-9530-5.

25. Akhter S, Husain SS, Chowdhury SA, Munzur MM and Dev GK (2006). Estimation of variance components and prediction of breeding value for some economically important traits of Black Bengal goat. Bangladesh Journal of Animal Science. 35: 20-26. 